\title{
The Mechanism of Entrepreneurship Education on College' Entrepreneurial Intention
}

\author{
Qilin Li \\ Enrollment and employment department, Neijiang Normal University, Neijiang, Sichuan 641000) \\ zjc1097@163.com
}

Keywords: Entrepreneurship education; Entrepreneurial attitude; Entrepreneurial intention; Innovation consciousness

\begin{abstract}
Now, the research on entrepreneurial intention is gradually becoming the focus of the academic research, and the entrepreneurship education is very important for college students. The article studies form the acquisition of entrepreneurship education effect, and use the aid of attitude-intention to prove the influence of the entrepreneurship education in colleges and universities for students' entrepreneurial intention. The results of the survey show that entrepreneurship education does help to improve students' entrepreneurial attitude and entrepreneurial intention. Entrepreneurial ambition inspiring and innovation consciousness awakening is the most apparent to the promotion of entrepreneurial intention .And innovation consciousness awaken indirectly influence the entrepreneurial intention through entrepreneurial attitude. This thesis put forward that entrepreneurship education in the future should departure from the students' innovative spirit and personality, inspiring their achievement motivation and cultivating the students' entrepreneurial spirit.
\end{abstract}

\section{Introduction}

In 2014, Premier Li Keqiang put forward "Bring about public entrepreneurship, grassroots entrepreneurial new wave "in the world economy BBS in Davos, the slogan improve the innovative point of view. Continued economic growth need more entrepreneurs involved in the business, creating "a guest of the classic era". Entrepreneurship is not only alleviating the pressure of the college students' employment but also can promote the university students' employment. And this is important for innovation and economic development. [1]

Entrepreneurial intention as a kind of potential subjective attitude, is a description for their entrepreneurial activities engaged in entrepreneurship. In this context, our country also established the development strategy that "high capacity for independent innovation, building an innovative country". ${ }^{[2]}$ The realization of the innovation is based on entrepreneurship. And entrepreneurship can also lead to the development of employment. College students are not only the one of the most creative potential crowd but also the most potential business group. So, if you want to achieve "to create industry to create more employment opportunities" goal, researching the entrepreneurial intention of college students is a very important task. Entrepreneurship education of college students can promote the formation of entrepreneurial culture in social life and improve college students' entrepreneurial initiative, enthusiasm, and promote business potential in the future. ${ }^{[3]}$

\section{Research Background and Hypothesis}

College Students' Entrepreneurial Attitude and Entrepreneurial Intention. College students' entrepreneurial attitude refers to the overall view the college students hold about entrepreneurship. The intention can reflect a body' motivation that is put into consciously plan or action. Entrepreneurial intention is a state of mind that characterized by individual attention and behavior for self-employment, rather than the organization employs. [4] In entrepreneurship education 
research category, many scholars at home and abroad view entrepreneurial attitude as important entrepreneurial intention model to constructs. The empirical research data also further proves that the entrepreneurial attitude on significant role in the formation of entrepreneurial intention. Thus, put forward the assumption 1:

Hypothesis 1: College students' entrepreneurial attitude has a positive role for students' entrepreneurship. [5]

The Effect of the College Students' Entrepreneurship Education. Foreign entrepreneurship education, not only limited to the curriculum, but rather refers to a series of activities associated with business combinations, including the curriculum, business plan competition, the practice interaction and supportive school project, etc. But, now, the entrepreneurship education is still in the initial stage of development, and theory and practice is not enough. From the point of the research of entrepreneurship education, the abroad is also at the exploration stage, aiming at course description or trend summarized, rarely describe from the aspect of empirical test of entrepreneurship education effect. [6] And entrepreneurship education in our country is grafted from the abroad research, still staying in the curriculum, training objectives, lacking further theory ascension and empirical data. Therefore, test college students' entrepreneurship education from the aspect of the empirical the profit students can get and these results impacts on college students' entrepreneurial attitude and entrepreneurial intention is very necessary. Through research the American university MBA students, found that the management of the student elective course number is related with their entrepreneurial enthusiasm .So, put forward the hypothesized 2.The hypothesis 2: The higher the degree of knowledge acquisition, the better entrepreneurship ascend the students' entrepreneurial attitude. [7]

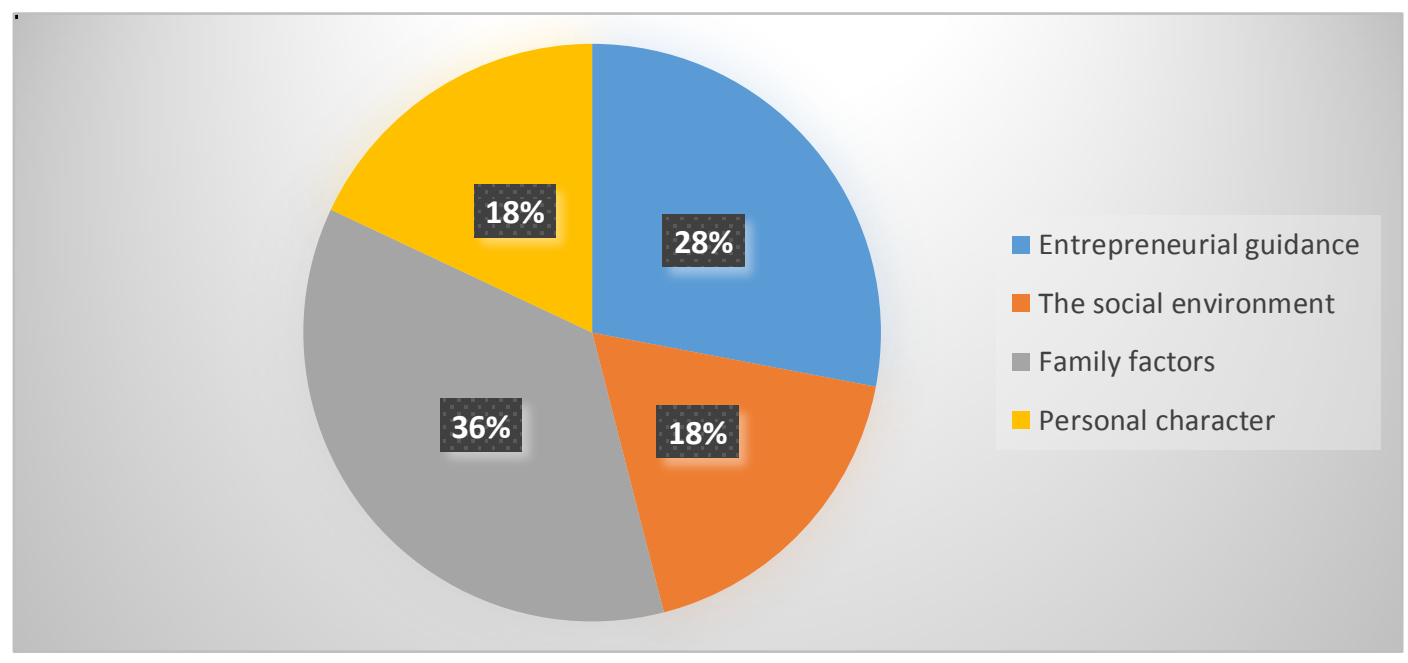

Figure 1. The influence factors on college students' entrepreneurial intention

\section{The Research Methods}

This investigation uses the form of random questionnaire. In order to ensure the questionnaire is scientific and effective, the author has repeatedly solicited opinions of the teachers in entrepreneurial management teaching team. We discussing the questionnaire, and select some students who just received entrepreneurship education to participate in forecast. We modify the part of the item, ensuring the questionnaire a high validity. We distributed 500 questionnaires in five universities. We take 400 effective samples, the effective rate was $80 \%$. The sex ratio of boy is $53.7 \%$ and the girl is $46.3 \%$. 


\section{The Empirical Result Analysis}

The Influence Factors of Entrepreneurial Intention. The questionnaire survey result show that the factors that affect college students' entrepreneurial intention is entrepreneurial guidance, social environment, family factors, personal character, etc. ${ }^{[8]} \mathrm{We}$ concluded that the following result by using single factor analysis. As is shown above, the effects of family factors on college students' entrepreneurial intention is first, accounting for $36 \%$. Effect of employment guidance for college students' entrepreneurial intention is at the second place, standing at $28 \%$. Environmental factors and the influence of entrepreneurial intention of college students for the college students personality effect is the same, at $18 \%$.

Common Method Bias (CMB). This research use HARMAN single factor test to check whether there is a common method bias. Put all measurement items into factor analysis. ${ }^{[9]}$ Under the conditions of the characteristic root is greater than 1 and do not making any rotating conditions, obtained the five factors. Transpose these and obtained minimum factor contribution rate of $13.739 \%$.The result is smaller than $30 \%$. The most major factor contribution rate is $63.022 \%$, more than $60 \%$. You could suggest that this study does not exist larger common method biases.

Model Fitting. Table 1 shows that the role of knowledge acquisition on the influence of entrepreneurial attitude and entrepreneurial intention is very weak. The direct impact on the entrepreneurial attitude at $\mathrm{p}<0.05$ just can get through the significance test. And the indirect influence to the entrepreneurial intention was not significant while remaining in (0.03).But the effect that knowledge acquisition has a positive effect to the promotion of entrepreneurial attitude (0.17). Ambition has directly impact on entrepreneurial intention. The influence coefficient is 0.32 , and, there is no significant relationship with entrepreneurial attitude. [9] Consciousness awakening in three endogenous latent variables affects entrepreneurial attitude and entrepreneurial intention. The biggest impact coefficient was 0.39 . The consciousness awakening that has direct effect on entrepreneurial intention. [10]

Table 1 effect coefficient between variables
Entrepreneurial attitude
Entrepreneurial intention

Directly affect indirectly affect the total influence Directly affect indirectly affect the total effect

\begin{tabular}{llllcc}
\hline KA & 0.17 & 0.17 & & 0.03 & 0.03 \\
IA & & & 0.32 & & 0.32 \\
CA & 0.39 & 0.39 & 0.21 & 0.07 & 0.39 \\
EA & & & 0.19 & & 0.19
\end{tabular}

NOTE: KA: Knowledge acquisition IA: inspired ambition CA: Consciousness awaken EA: Entrepreneurial attitude

\section{Summary}

Theoretical significance of the article is to verify Attitude and intention that the external factors (entrepreneurship education) for a particular behavior (self-employed). [4]At the same time, the article first proposed the localization environment acquisition effect of students' entrepreneurship education, providing theoretical support for the development of entrepreneurship education and 
empirical basis. The empirical result shows that entrepreneurship education for students' entrepreneurial intention affected considerably by encouraging students' entrepreneurial aspirations, enhancing the innovation consciousness of students, especially for the cultivation of their innovative consciousness and edification. The biggest difference that entrepreneurship education and traditional education is cultivating college students' independent personality and spirit The development of entrepreneurship education in the future not only aim at the students' employment , and shape students' innovative spirit.

\section{References}

[1] Limin Zhang, Chenjing Feng, Shuaiying Li. Taking Post Entrepreneurship Education as an Orientation: A Strategic Choice for the Development of Entrepreneurship Educational Transformation [A]. Information Engineering Research Institute, USA. Proceedings of 2014 4th International Conference on Applied Social Science(ICASS 2014 V52)[C].Information Engineering Research Institute, USA:,2014:6.

[2] Qianyun Kong, Yu Zhao, Qingli Zhao. Construction of Local University Students' Entrepreneurship Education System [A]. Information Engineering Research Institute, USA. Proceedings of 2014 4th International Conference on Applied Social Science(ICASS 2014 V52)[C].Information Engineering Research Institute, USA:,2014:5.

[3] Shengyong Yang, Shuo Zhang. Research and Exploration of the Entrepreneurship Education Practice of Agricultural Universities [A]. Information Engineering Research Institute, USA. Proceedings of 2014 2nd International Conference on Economic, Business Management and Education Innovation(EBMEI 2014 V40)[C].Information Engineering Research Institute, USA:,2014:4.

[4] Sasa Li. On the Positions and Roles of the Ideological and Political Education in the College Students' Entrepreneurship Education [A]. Singapore Management and Sports Science Institute, Singapore. Proceedings of 2015 3rd Asian Conference on the Social Sciences(Advances in Social and Behavioral Sciences Volume 15) [C].Singapore Management and Sports Science Institute, Singapore: 2015:5.

[5] $\mathrm{Na}$ Chen, XiaoQin Cai. Entrepreneurship education research in college and university based on tacit knowledge theory [A]. Information Engineering Research Institute, USA. Proceedings of 2014 2nd International Conference on Frontiers in Computer Education(ICFCE 2014 V1)[C].Information Engineering Research Institute, USA:,2014:4.

[6] Yun Sun. Innovation Strategy of College Students' Entrepreneurship Education in Modern Times [A]. International Informatization and Engineering Associations 、Atlantis Press. Proceedings of 2015 International Conference on Management Science, Education Technology, Arts, Social Science and Economics (MSETASSE 2015)[C].International Informatization and Engineering Associations, Atlantis Press: 2015:4.

[7] Liucheng Zhang. Research of Innovation and Entrepreneurship Education in Harbin University of Commerce [A]. Singapore Management and Sports Science Institute, Singapore. Proceedings of 2015 3rd International Conference on Social Science and Humanity(ICSSH 2015 V76)[C].Singapore Management and Sports Science Institute, Singapore:,2015:4.

[8] Junzheng Wang, Guixue Hu. The Essence of the Entrepreneurship Education and the Perfection of the System of the Entrepreneurship Education in Colleges and Universities [A]. Singapore Management and Sports Science Institute, Singapore. Proceedings of 2015 SSR International Conference on Social Sciences and Information(SSR-SSI 2015 V11)[C].Singapore Management and Sports Science Institute, Singapore: 2015:6. 
[9] Pingting Huang, Chun Fan. The Analysis on Entrepreneurship Education Model in Vocational Colleges [A]. Information Engineering Research Institute, USA. Proceedings of 2014 2nd International Conference on Social Science and Health (ICSSH 2014 V55) [C].Information Engineering Research Institute, USA: 2014:5.

[10]Fei Yu. Exploration of Practical Predicament in Entrepreneurship Education Faced by Vocational Colleges of Jilin Province [A]. Singapore Management and Sports Science Institute, Singapore. Proceedings of 2015 3rd International Conference on Social Sciences Research(SSR 2015 V13)[C].Singapore Management and Sports Science Institute, Singapore: 2015:5. 